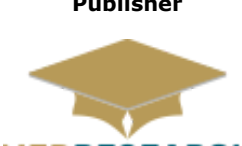

MEDRESEARCH

www.medresearch.in
Research and Review

2021 Volume 9 Number 2 March-April

\title{
Myocardial Dysfunction in Elderly Patients Admitted with Non-Cardiac Diagnosis in Intensive Care Unit
}

\author{
Yeshavanth G. ${ }^{1}$, Joy E. ${ }^{2 *}$, Bhagavath A. ${ }^{3}$ \\ DOI: https://doi.org/10.17511/ijmrr.2021.i02.13
}

1 Yeshavanth G., Associate Professor, S.S. Institute of Medical Sciences and Research Centre, Davangere, Karnataka, India.

2* Edwin Joy, Post Graduate, S.S. Institute of Medical Sciences and Research Centre, Davangere, Karnataka, India.

${ }^{3}$ Aravind Bhagavath, Post Graduate, S.S. Institute of Medical Sciences and Research Centre, Davangere, Karnataka, India.

Background and Objectives: The diagnosis of acute coronary syndromes can be challenging in patients admitted with the non-cardiac disease to the Intensive Care Unit (ICU). The study aimed to determine the clinical profile of critically ill elderly patients developing myocardial injury who were admitted to ICU for non-cardiac diagnosis. Materials and Methods: The retrospective study subjects are 130 patients admitted to the medical ICU. Within 24 hours of admission to ICU a detailed history, a 12 lead ECG, CK-MB, Cardiac troponin T was done and as required based on ECG findings and development of clinical symptoms. Results: Our study showed that 35 out of 130 patients developed acute myocardial injury. 13 out of 35 patients who had myocardial injury had a fatal outcome. The prevalence of hypertension, diabetes mellitus, history of CVA, history of IHD and COPD reached statistical significance $(p<0.001)$ between the two groups of patients who developed myocardial injury and who did not develop a myocardial injury. In patients with multiple comorbidities, the presence of factors like hypoxia, hypotension and the use of vasopressors increases the risk of mortality. Conclusion: All elderly patients who are hospitalized with or without multiple comorbidities with an acute form of stressors must be evaluated aggressively for precipitants and adequately treated to prevent myocardial injury.

Keywords: Myocardial dysfunction, Elderly Patients, Non-cardiac cause

\section{Corresponding Author}

Edwin Joy, Post Graduate, S.S. Institute of Medical Sciences and Research Centre, Davangere, Karnataka, India.

Email: edwin.joy1@gmail.com

\section{How to Cite this Article}

Yeshavanth G, Joy E, Bhagavath A. Myocardial Dysfunction in Elderly Patients Admitted with NonCardiac Diagnosis in Intensive Care Unit. Int J Med Res Rev. 2021;9(2):129-134.

Available From

https://ijmrr.medresearch.in/index.php/ijmrr/article/ view/1262
To Browse

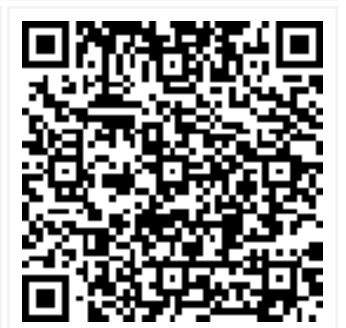

Manuscript Received 2021-03-04

Conflict of Interest No
Review Round 1 2021-03-14

Funding Nil

Review Round 2
2021-03-27
Ethical Approval
Yes

Review Round 3

Plagiarism X-checker $6 \%$
Accepted 2021-04-04

Note

(c) 2021 by Yeshavanth G., Edwin Joy, Aravind Bhagavath and Published by Siddharth Health Research and Social Welfare Society. This is an Open Access article licensed under a Creative Commons Attribution 4.0 International License https://creativecommons.org/licenses/by/4.0/ unported [CC BY 4.0]. 


\section{Introduction}

So this study aims to evaluate the clinical profile of patients developing myocardial injury assessed by raised cardiac troponin T, ECG findings in critically ill elderly patients admitted to ICU for non-cardiac diagnosis. In other studies, the identification of those at risk for AMI for patients admitted to the ICU for non-cardiac reasons was mainly due to the concomitant conditions that can prevent an appropriate screening. In their study, the diagnostic discrepancy was higher in septic patients, in whom the correct diagnosis of AMI was established at a rate lower than $50 \%$ of cases as compared with non-septic patients [3].

Elderly patients who are critically ill are at high risk for myocardial ischemia because of older age, hypoxia, increased intrinsic and extrinsic sympathetic stimulation, coagulation disorders and vasopressor use [1]. The diagnosis of myocardial ischemia in ICU patients in clinical practice is difficult because of the presence of confounding comorbidities and the absence of clinical symptoms. So Myocardial infarction (MI) in critically ill patients is a diagnostic challenge and is associated with adverse outcome for the patient [2]. The presence of elevated CTn, in addition to ECG changes, would help in deciding to rule in or out Myocardial injury.

\section{Methodology}

In a retrospective study conducted in a tertiary care hospital, 130 Elderly patients admitted to medical ICUs with a non-cardiac diagnosis were included in the study. This study was conducted in the Department of General Medicine, SSMIS \& RC, Davangere, Karnataka, India.

\section{Aims and Objectives}

- To study myocardial injury in critically ill elderly patients admitted to ICU with non-cardiac diagnosis.

- To identify what are the precipitants for myocardial injury in critically ill elderly ICU patients

- To study their clinical profile and outcome at the time of discharge from ICU.

\section{Inclusion Criteria}

- Age more than 60years.

- Patients admitted to ICU with critical noncardiac illness.

\section{Exclusion Criteria}

- Patients presenting with primary cardiac diagnosis at admission.

- Patients with post-cardiac surgery, admitted with thoracic trauma with a high likelihood of myocardial injury, coexisting renal failure.

\section{Method of Collection of Data}

- On admission to ICU a detailed clinical history, basic investigations, a 12 lead ECG was done.

- Within 24 hours of admission to ICU, Cardiac troponin T, CK-MB was done and repeated as required, based on ECG findings and development of clinical symptoms.

- The patient was on continuous ECG monitoring of lead II and 12 lead ECG was repeated based on fresh ST-segment changes and clinical symptoms of cardiac injury after admission.

\section{Statistical analysis:}

Categorical variables were expressed as frequency \& amplitude; percentages. Continuous variables

Were expressed as mean \pm standard deviation. To assess the mean difference between groups unpaired $\mathrm{t}$

Test was performed. The value of $P<0.05$ was considered statistically significant.

Statistical Package for the Social Sciences (SPSS) version 22 (IBM) for windows was used for analyses.

\section{Results}

A total of 130 patients were studied. The study shows that in 52 patients out of the 130 had pneumonia, 18 of the subjects had acute gastroenteritis, 14 of them had Diffuse compensated liver disease, 12 of them had cellulitis, 11 had Cerebrovascular accident, 5 of them had cancer, 11 of them had urosepsis, and 7 of them had hypoglycemia as mentioned in table 1.

Among the subjects involved in the study $57.7 \%$ were diabetic, $59.2 \%$ were hypertensive. Around $38.4 \%$ were both diabetic and hypertensive. $25.4 \%$ of them had a h/o CVA. $13.1 \%$ of them suffer from COPD. $17.7 \%$ of the subjects in the study had $\mathrm{h} / \mathrm{o}$ bronchial asthma. $30.8 \%$ of the subjects involved in the study had dyslipidemia.14.6\% of them suffered from hypothyroidism.20.8\% of the individuals had a h/o alcoholism and $22.3 \%$ of them had a history of smoking as mentioned in table 2 . 
In the total of the 130 subjects involved in study 26 of the subjects had a positive CKMB and Troponin $T$ and 104 subjects were negative for CKMB and Trop $\mathrm{T}$ as mentioned in table 3.

Table 4 shows the associations of clinical variables about the myocardial injury. There were 80 male subjects in the study and 50 female subjects in the study. In the study performed 75 subjects were diabetic, 77 of the subjects were hypertensive. 49 individuals and 33 individuals had a history of old ischemic heart disease and old cerebrovascular accident.27 subjects involved in the study had a history of chronic alcoholism.29 subjects in the study had a history of smoking. Chronic obstructive pulmonary disease and asthma was present in 17 and 23 individuals involved in the study respectively.40 individuals blood workup showed dyslipidemia. 19 of the individuals in the study had hypothyroidism.

There was no anaemia in 76 individuals involved in the study. 22 of them had mild anemia and 22 of them had moderate anemia. 10 subjects in the study had severe anemia.

Table 5 shows the association of non-cardiac injury with myocardial injury. Out of the 52 individuals having pneumonia15 of them had a myocardial injury. The 18 subjects had gastroenteritis 7 of them had a myocardial injury. 12 subjects had cellulitis of which 2 had a myocardial injury. 7 subjects had hypoglycemic episodes and 2 of them had a myocardial injury. There were 5 cancer patients out of which 1 had a myocardial Injury. There were 11 CVA and urosepsis cases admitted in the critical care unit out of which only 1 had a myocardial injury.

Table 6 shows the association of clinical variables about the outcome of patients with myocardial injury. 35 subjects had myocardial infarction out of which 13 of the individuals succumbed suffered from type 2 diabetes mellitus, hypertension and old ischemic heart disease.13 of them had hypotension and needed inotropic support. 11 subjects in the study who did not survive had a history of cerebrovascular accident. The $\mathrm{HBa} 1 \mathrm{C}$ had a mean of 8.95 and a standard deviation of 2.30 among the dead. The mean of $\mathrm{HBa} 1 \mathrm{c}$ among the survivors of myocardial infarction 7.21 and the standard deviation 0.64. The mean PO2 among the dead was 46 with a standard deviation of 26 . The mean PO2 among the survivors of myocardial infarction was 66 with a standard deviation of 16 .
Table 1: ICU diagnosis of patients studied

\begin{tabular}{|l|l|l|}
\hline \multicolumn{1}{|c|}{ Diagnosis } & \multicolumn{1}{c|}{ No. of patients } & \multicolumn{1}{c|}{$\%$} \\
\hline Pneumonia & 52 & 40.8 \\
\hline Acute gastroenteritis & 18 & 13.8 \\
\hline DCLD & 14 & 10.8 \\
\hline Cellulitis & 12 & 9.2 \\
\hline CVA & 11 & 8.5 \\
\hline Cancer & 5 & 3.8 \\
\hline Urospesis & 11 & 8.5 \\
\hline Hypoglycemia & 7 & 5.4 \\
\hline Total & 130 & 100.0 \\
\hline
\end{tabular}

Table 2: Incidence of co-morbidities in patients studied

\begin{tabular}{|l|l|l|}
\hline & \multicolumn{1}{|c|}{ No. of patients $(\mathbf{n = 1 3 0 )}$} & $\%$ \\
\hline T2DM & 75 & 57.7 \\
\hline HTN & 77 & 59.2 \\
\hline T2DM+HTN & 50 & 38.4 \\
\hline OLD CVA & 33 & 25.4 \\
\hline COPD & 17 & 13.1 \\
\hline Asthma & 23 & 17.7 \\
\hline Dyslipidemia & 40 & 30.8 \\
\hline Hypothyroidism & 19 & 14.6 \\
\hline Alcohol & 27 & 20.8 \\
\hline Smoking & 29 & 22.3 \\
\hline
\end{tabular}

Table 3: CKMB and TROP T during ICU stay in patients at the onset of symptoms

\begin{tabular}{|l|l|l|l|}
\hline \multirow{2}{*}{ CKMB \& TROP T on follow-up } & \multicolumn{2}{|c|}{ Symptoms } & \multirow{2}{*}{ Total } \\
\cline { 2 - 3 } & No & Yes & \\
\hline Negative & $69(98.6 \%)$ & $35(58.3 \%)$ & $104(80 \%)$ \\
\hline Positive & $1(1.4 \%)$ & $25(41.7 \%)$ & $26(20 \%)$ \\
\hline Total & $70(100 \%)$ & $60(100 \%)$ & $130(100 \%)$ \\
\hline
\end{tabular}

Table 4: Association of Clinical variables in relation to Myocardial Injury

\begin{tabular}{|l|l|l|l|l|}
\hline \multirow{2}{*}{ Variables } & \multicolumn{2}{|c|}{ Myocardial Injury } & \multirow{2}{*}{ Total $(\mathrm{n}=130)$} & \multirow{2}{*}{ P value } \\
\cline { 2 - 3 } & Yes $(\mathrm{n}=35)$ & No $(\mathrm{n}=95)$ & & \\
\hline Male & $24(68.6 \%)$ & $56(58.9 \%)$ & $80(61.5 \%)$ & 0.317 \\
\hline Female & $11(31.4 \%)$ & $39(41.1 \%)$ & $50(38.5 \%)$ & 0.317 \\
\hline T2DM & $34(97.1 \%)$ & $41(43.2 \%)$ & $75(57.7 \%)$ & $<0.001^{* *}$ \\
\hline HTN & $33(94.3 \%)$ & $44(46.3 \%)$ & $77(59.2 \%)$ & $<0.001^{* *}$ \\
\hline Old IHD & $29(82.9 \%)$ & $20(21.1 \%)$ & $49(37.7 \%)$ & $<0.001^{* *}$ \\
\hline Old CVA & $21(60 \%)$ & $12(12.6 \%)$ & $33(25.4 \%)$ & $<0.001^{* *}$ \\
\hline Alcohol & $13(37.1 \%)$ & $14(14.7 \%)$ & $27(20.8 \%)$ & $0.005^{* *}$ \\
\hline Smoking & $17(48.6 \%)$ & $12(12.6 \%)$ & $29(22.3 \%)$ & $<0.001^{* *}$ \\
\hline COPD & $12(34.3 \%)$ & $5(5.3 \%)$ & $17(13.1 \%)$ & $<0.001^{* *}$ \\
\hline Asthma & $3(8.6 \%)$ & $20(21.1 \%)$ & $23(17.7 \%)$ & $0.098+$ \\
\hline Dyslipidemia & $19(54.3 \%)$ & $21(22.1 \%)$ & $40(30.8 \%)$ & $<0.001^{* *}$ \\
\hline Hypothyroidism & $9(25.7 \%)$ & $10(10.5 \%)$ & $19(14.6 \%)$ & $0.030 *$ \\
\hline Hypotension & $24(68.5 \%)$ & $40(42 \%)$ & $64(49.2 \%)$ & 0.040 \\
\hline Nil anemia & $9(25.7 \%)$ & $67(70.5 \%)$ & $76(58.5 \%)$ & 0.125 \\
\hline
\end{tabular}


Yeshavanth G. et al: Myocardial Dysfunction in Elderly Patients

\begin{tabular}{|l|l|l|l|l|}
\hline Mild anemia $(11-12 \mathrm{~g} / \mathrm{dl})$ & $3(8.6 \%)$ & $19(20 \%)$ & $22(16.9 \%)$ & 0.094 \\
\hline Moderate anemia $(8-10.9 \mathrm{~g} / \mathrm{dl})$ & $15(42.9 \%)$ & $7(7.4 \%)$ & $22(16.9 \%)$ & $<0.001 * *$ \\
\hline Severe anemia $(<8 \mathrm{~g} / \mathrm{dl})$ & $8(22.9 \%)$ & $2(2.1 \%)$ & $10(7.7 \%)$ & $<0.001 * *$ \\
\hline HbA1c \% & $8.85 \pm 2.30$ & $7.41 \pm 0.64$ & $8.05 \pm 1.75$ & $<0.001 * *$ \\
\hline PO2 $(\mathrm{mmHg})$ & $52 \pm 21$ & $76 \pm 14$ & $66 \pm 16$ & $0.004 * *$ \\
\hline S. sodium $(\mathrm{mEq} / \mathrm{dl})$ & $128 \pm 3$ & $131 \pm 5$ & $129 \pm 6$ & 0.218 \\
\hline S. potassium(mEq/dl) & $3.6 \pm 1.1$ & $4.0 \pm 0.8$ & $3.8 \pm 0.9$ & 0.318 \\
\hline
\end{tabular}

Table 5: Association of non-cardiac diagnosis with myocardial injury

\begin{tabular}{|c|c|c|c|c|}
\hline |Diagnosis & $\begin{array}{c}\text { Patients with } \\
\text { myocardial injury } \\
(\mathrm{n}=35)\end{array}$ & $\begin{array}{l}\text { Patients without } \\
\text { myocardial injury } \\
\qquad(n=95)\end{array}$ & $\begin{array}{c}\text { Total } \\
(n=130)\end{array}$ & $\begin{array}{c}\mathrm{P} \\
\text { value }\end{array}$ \\
\hline Pneumonia & $15(42.8 \%)$ & $37(38.9 \%)$ & $52(40 \%)$ & 0.916 \\
\hline $\begin{array}{l}\text { Acute } \\
\text { gastroenter } \\
\text { itis }\end{array}$ & $7(20 \%)$ & $11(11.5 \%)$ & $18(13.8 \%$ & 0.217 \\
\hline DCLD & $6(17.1 \%)$ & $8(8.4 \%)$ & $14(10.7 \%$ & 0.08 \\
\hline Cellulitis & $2(5.7 \%)$ & $10(10.5 \%)$ & $12(9.2 \%)$ & 0.760 \\
\hline $\begin{array}{l}\text { Hypoglyce } \\
\text { mia }\end{array}$ & $2(5.7 \%)$ & $5(5.2 \%)$ & $7(5.3 \%)$ & 0.90 \\
\hline Cancer & $1(2.8 \%)$ & $4(4.2 \%)$ & $5(3.2 \%)$ & 0.817 \\
\hline CVA & $1(2.8 \%)$ & $10(10.5 \%)$ & $11(8.4 \%)$ & 0.716 \\
\hline Urosepsis & $1(2.8 \%)$ & $10(10.5 \%)$ & $11(8.4 \%)$ & 0.851 \\
\hline
\end{tabular}

Figure 1: Association of comorbidities with myocardial injury

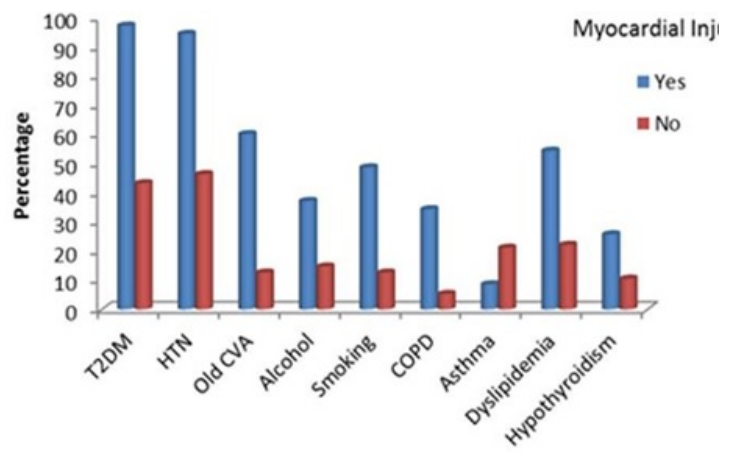

Table 6: Association of clinical variables in relation to outcome in patients with myocardial injury

\begin{tabular}{|l|l|l|l|}
\hline \multirow{2}{*}{ Variables } & \multicolumn{2}{|c|}{ Myocardial Injury } & \multirow{2}{*}{ P value } \\
\cline { 2 - 3 } & Death $(n=13)$ & Survived $(n=22)$ & \\
\hline Male & $8(61.5 \%)$ & $16(72.7 \%)$ & 0.417 \\
\hline Female & $5(38.4 \%)$ & $6(27.2 \%)$ & 0.517 \\
\hline T2DM & $13(100 \%)$ & $21(95.4 \%)$ & 0.42 \\
\hline HTN & $13(100 \%)$ & $20(90.9 \%)$ & 0.38 \\
\hline Old IHD & $13(100 \%)$ & $16(72.7 \%)$ & $0.03 *$ \\
\hline Old CVA & $11(84.6 \%)$ & $10(45.4 \%)$ & $<0.001 * *$ \\
\hline Alcohol & $4(30.8 \%)$ & $9(40.9 \%)$ & 0.521 \\
\hline Smoking & $7(53.8 \%)$ & $10(45.4 \%)$ & 0.480 \\
\hline
\end{tabular}

\begin{tabular}{|l|l|l|l|}
\hline COPD & $5(38.4 \%)$ & $7(31.8 \%)$ & 0.612 \\
\hline Asthma & $3(23.0 \%)$ & $0 \%$ & $0.040^{*}$ \\
\hline Dyslipidemia & $9(69.2 \%)$ & $10(45.4 \%)$ & $0.021^{*}$ \\
\hline Hypothyroidism & $4(30.8 \%)$ & $5(22.7 \%)$ & 0.061 \\
\hline Hypotension & $13(100 \%)$ & $17(77.2 \%)$ & $0.021^{* *}$ \\
\hline Nil anemia & $1(7 \%)$ & $8(36.3 \%)$ & 0.125 \\
\hline Mild anemia(11-12g/dl) & $0 \%$ & $3(13.6 \%)$ & 0.941 \\
\hline Moderate anemia(8- $10.9 \mathrm{~g} / \mathrm{dl})$ & $6(46.1 \%)$ & $9(40.9 \%)$ & 0.681 \\
\hline Severe anemia(<8g/dl) & $6(46.1 \%)$ & $2(9 \%)$ & $<0.001^{* *}$ \\
\hline HbA1c $\%$ & $8.95 \pm 2.30$ & $7.21 \pm 0.64$ & $<0.001^{* *}$ \\
\hline PO2 $(\mathrm{mmHg})$ & $46 \pm 26$ & $66 \pm 16$ & $0.004 * *$ \\
\hline S. sodium $(\mathrm{mEq} / \mathrm{dl})$ & $128 \pm 4$ & $132 \pm 3$ & 0.218 \\
\hline S. potassium(mEq/dl) & $3.6 \pm 0.8$ & $3.8 \pm 1.1$ & 0.318 \\
\hline
\end{tabular}

\section{Discussion}

The typical signs and symptoms of ischemia can be difficult to appreciate and surrogate physiological markers of impaired coronary perfusion are masked or misinterpreted in the context of the index pathology[2]. So Myocardial infarction (MI) is a diagnostic challenge in critically ill patients and is associated with adverse outcome[3]. In our study the incidence of myocardial injury in patients admitted to intensive care unit with the non-cardiac diagnosis was $37.1 \%$. According to Lim et al, $25.8 \%$ of elderly patients admitted to ICU had myocardial injury[4]. Atypical presentations of myocardial ischemia include atypical chest pain, acute confusion, shortness of breath, vomiting can be a manifestation of myocardial injury in critically ill elderly patients. Among many symptoms, in our study dyspnea $(46.7 \%)$ appeared to be the most common symptom, followed by altered sensorium $(25 \%)$ and fatigue (20\%). A study conducted by Venkatesh, et al. also showed atypical symptoms like epigastric pain, breathlessness, burning sensation and fatigue are common presenting complaints in elderly patients diagnosed with AMI [5].

In our study pneumonia was the most common ICU diagnosis in patients who developed myocardial injury $(42.8 \%)$ as shown in table 5 . Our results were correlating with a study done by Ostermann et al where the most common non-cardiac diagnosis was sepsis secondary to pneumonia (40\%)[6]. In our study there was a statistically significant relationship between the presence of the following co-morbidities and patients who had a myocardial injury $\quad(p<0.001 *) \quad 1$. Diabetes $(97 \%) \quad 2$. Hypertension (94\%) 3.Past history of IHD (83\%) 4.Past history of CVA (60\%) 5.COPD (34\%) 6.Dyslipidemia (54.3\%) 6. Hypothyroidism (25.7\%). 
The presence of comorbidities in the subjects studied is shown in table 2 . The cardiac troponin $T$ levels and CKMB levels in the individuals participating in the study are shown in table 3. It was observed that the mean TSH value in the study in patients with hypothyroidism who had myocardial injury was $0.94 \mathrm{IU} / \mathrm{ml}$ and who did not develop myocardial injury was $3.46 \mathrm{IU} / \mathrm{ml}$ which was statistically significant $(p=0.002)$. In our study the incidence of myocardial injury and all cause mortality was found to co-relate with: (1) Use of vasopressor agents for maintaining adequate tissue perfusion $(p=0.04)$, which was consistent with a study done by Liu et al $(p=0.03)$ [7]. (2) Anemia (significant in patients with moderate and severe anaemia) with $p=0.001$, similar to a study done by Fabio et al. $(p=0.002)[8]$.

(3) Hypoxia: Mean po2 values were between 45-55 $\mathrm{mmHg}$ in patients who had myocardial injury and death in our study $(p=0.001)$ which was consistent with a study done by Fabio et al. $(p=0.003)$ [8]. (4) The blood sugar level at the onset of symptoms when patients had myocardial injury ranged between 90 and $460 \mathrm{mg} / \mathrm{dl}$, signifying both hypoglycemia and hyperglycemia were risk factors for myocardial injury in the present study $(p=0.002)$. A study done by Subramanyan et al showed similar results $(p=0.001)[9]$. In the present study, HbA1C $>8.5$ was associated with a significant incidence of myocardial injury and death $(p<0.001)$, which was consistent with a study done by Mahmut et al $(p=0.004)$ [12]. In the present study in patients who had a myocardial injury there was no significant correlation between serum sodium and potassium levels $(p=0.218$ and $p=0.318)$ respectively. The results are consistent with the study done by Micheal Liu et $\mathrm{al}(\mathrm{p}=0.080)$ and Verma et $\mathrm{al}(p=0.41)[7]$, But in a study done by Goldberg $A$ et al there was a significant co-relation between hyponatremia and hypokalemia about myocardial injury $(p=0.02)$ [11].

\section{Conclusion}

The commonly found comorbidity include Diabetes Mellitus, Hypertension, Obstructive airway disease, Hypothyroidism and decompensated chronic liver disease in various combinations. In patients who had a myocardial injury, the parameters related to these comorbidities were poorly controlled. These results were consistent with the study conducted by Alatasi A et al [13].
The below-mentioned factors could be precipitating factors for myocardial ischemia in an elderly individual.

- Hypoglycemia and Hyperglycemia

- Hypoxemia

- Hypotension with use of vasopressor agents

- Poorly supplemented hypothyroidism

- Anemia

The above triggering factors are fortunately easily treatable and preventable. Hence all elderly patients who are hospitalized with an acute form of stressors with or without multiple comorbidities must be aggressively evaluated for precipitating factors and adequately treated. Strategies recommended for timely diagnosis and intervention of myocardial dysfunction in intensive care include

- daily 12 lead ECG monitoring,

- troponin I and CK-MB on admission and once in 72 hrs,

- use of echocardiography to identify myocardial dysfunction when there is an elevation of cardiac markers.

Further studies are required to validate the relations between myocardial dysfunction and the abovementioned individual precipitating factors.

\section{What does the study add to existing knowledge?}

Hypoglycemia and Hyperglycemia, Hypoxemia, Hypotension with the use of vasopressor agents \& Poorly supplemented hypothyroidism are major precipitating factors for myocardial ischemia in an elderly individual.

\section{Author contributions}

YG, EJ collected the data and conducted this study. $A B$ and EJ did data analysis. YG, EJ did manuscript drafting. All authors were involved in revising and approved the final version of the manuscript.

\section{Reference}

01. Klouche K, Jonquet O, Cristol JP. The diagnostic challenge of myocardial infarction in critically ill patients- do high-sensitivity troponin measurements add more clarity or more confusion?. Crit Care. 2014 Jun 5;18(3)148.

doi: $10.1186 /$ cc13909 [Crossref] 
02. Webb I, Coutts J. Myocardial infarction on the ICU- can we do better?. Crit Care. $2008 ; 12(2) 129$.

doi: $10.1186 /$ cc6832 [Crossref]

03. Berlot G, Vergolini A, Calderan C, Bussani R, Torelli L, Lucangelo $U$. Acute myocardial infarction in non-cardiac critically ill patients- a clinical-pathological study. Monaldi Arch Chest Dis. 2010 Dec;74(4)164-71.

doi: $10.4081 /$ monaldi.2010.257 [Crossref]

04. Lim W, Cook DJ, Griffith LE, Crowther MA, Devereaux PJ. Elevated cardiac troponin levels in critically ill patients- prevalence, incidence, and outcomes. Am J Crit Care. 2006 May;15(3)280-8; quiz 289.

[Crossref]

05. Venkatesh CR, Kiran HS, Murthy KAS, Gowdappa BH. Clinical Profile of Atypical Manifestations of Diseases in Elderly Patients Admitted to Critical Care Areas. Int J Sci Stud. 2015;3(7)254-58.

[Crossref]

06. Ostermann M, Lo J, Toolan M, Tuddenham E, Sanderson B, Lei K, Smith J, Griffiths A, Webb I, Coutts J, Chambers J, Collinson P, Peacock J, Bennett D, Treacher D. A prospective study of the impact of serial troponin measurements on the diagnosis of myocardial infarction and hospital and six-month mortality in patients admitted to ICU with non-cardiac diagnoses. Crit Care. 2014 Apr 4;18(2)R62.

doi: $10.1186 /$ cc13818 [Crossref]

07. Liu M, Shehu M, Herrold E, Cohen H. Prognostic value of initial elevation in cardiac troponin I level in critically ill patients without acute coronary syndrome. Crit Care Nurse. 2015 Apr;35(2)e1-10.

doi: $10.4037 / \operatorname{ccn} 2015300$ [Crossref]

08. Bellotto F, Fagiuoli S, Pavei A, Gregory SA, Cati A, Silverj E, Plebani M, Zaninotto M, Mancuso T, Iliceto $S$. Anemia and ischemia: myocardial injury in patients with gastrointestinal bleeding. Am J Med. 2005 May;118(5)548-51.

doi: 10.1016/j.amjmed.2005.01.026 [Crossref]
09. Senthilkumaran S, Meenakshisundaram R, Ponnuswamy S, Thirumalaikolundusubramanian P. Hypoglycemia and myocardial infarctionInhibition of ischemic preconditioning response. Indian J Endocrinol Metab. 2012 May; 16(3)4734.

doi: $10.4103 / 2230-8210.95723$ [Crossref]

10. Cakmak M, Cakmak N, Cetemen S, Tanriverdi $H$, Enc $Y$, Teskin O, Kilic ID. The value of admission glycosylated hemoglobin level in patients with acute myocardial infarction. Can J Cardiol. 2008 May;24(5)375-8.

doi: $10.1016 / \mathrm{s} 0828-282 \times(08) 70600-7$ [Crossref]

11. Goldberg A, Hammerman $H$, Petcherski $S$, Zdorovyak A, Yalonetsky $S$, Kapeliovich $M$, Agmon $Y$, Markiewicz W, Aronson D. Prognostic importance of hyponatremia in acute STelevation myocardial infarction. Am J Med. 2004 Aug $15 ; 117(4) 242-8$.

doi: 10.1016/j.amjmed.2004.03.022 [Crossref]

12. Cakmak M, Cakmak N, Cetemen S, Tanriverdi H, Enc $Y$, Teskin $O$, Kilic ID. The value of admission glycosylated hemoglobin level in patients with acute myocardial infarction. Canadian journal of cardiology. 2008 May 1;24(5)375-8.

[Crossref]

13. Alatassi A, Habbal M, Tamim H, Sadat M, Al Qasim $E$, Arabi YM. Association between troponin-I levels and outcome in critically ill patients admitted to non-cardiac intensive care unit with high prevalence of cardiovascular risk factors. BMC anesthesiology. 2018 Dec;18(1)11.

[Crossref] 